\title{
Crises de representação
}

\section{Paulo Eduardo Carvalho}

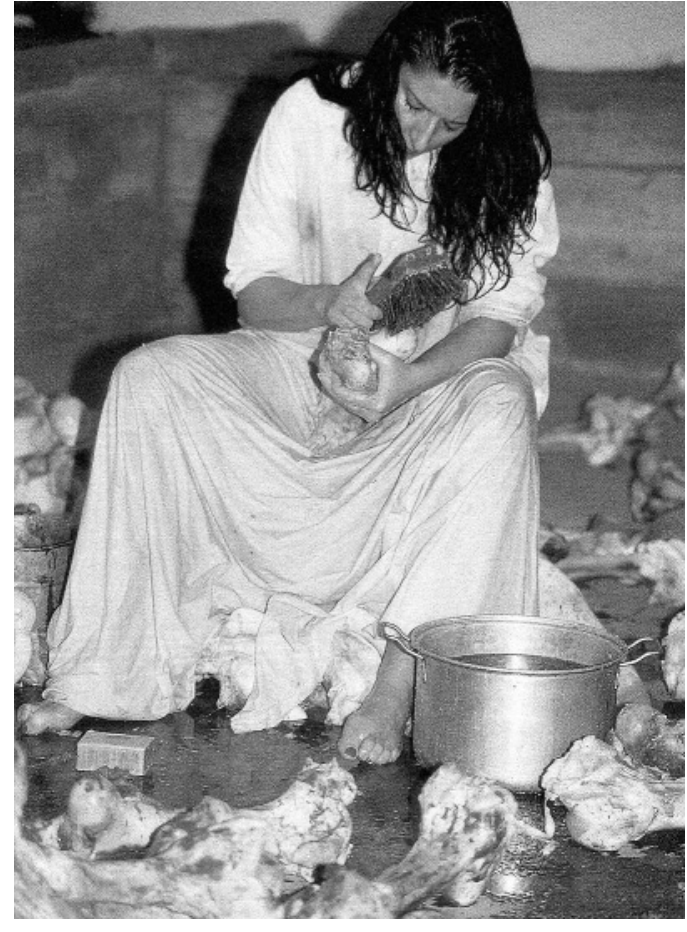

Num dos 17 "argumentos" que integram a peça de Martin Crimp (A)tentados (Attempts on Her Life, 1997), um conjunto de vozes anónimas discute a obra de uma artista suicidária. 0 objecto da sua discussão acesa é a exibição pública de uma colecção de objectos, muito à maneira de alguns dos artistas britânicos associados com a histórica exposição Sensation: Young British Artists from the Saatchi Collection ${ }^{2}$, apresentada na Royal Academy of Arts, entre 28 de Setembro e 28 de Dezembro de 1997:

- Aquilo que vemos aqui são diversos objectos associados com as tentativas de suicidio da artista durante os últimos meses. Por exemplo: frascos de remédios, registos de internamentos hospitalares, polaróides dos diversos homens seropositivos com quem ela teve deliberadamente relações sexuais não protegidas, bocados de vidro partido...

- Bilhetes de suicidio.

- ...sim, e as paredes da galeria foram, é claro, revestidas com muitos dos seus bilhetes de suicidio. Além das polaróides, existem uns registos video assaz "desagradáveis", devo dizê-lo, dessas mesmas tentativas. (Crimp 2000: 186)
Se decidirmos nunca usar a violência continuaremos sem ter feito nada para tornar o mundo menos violento. (Bond 1977: 17) ${ }^{1}$

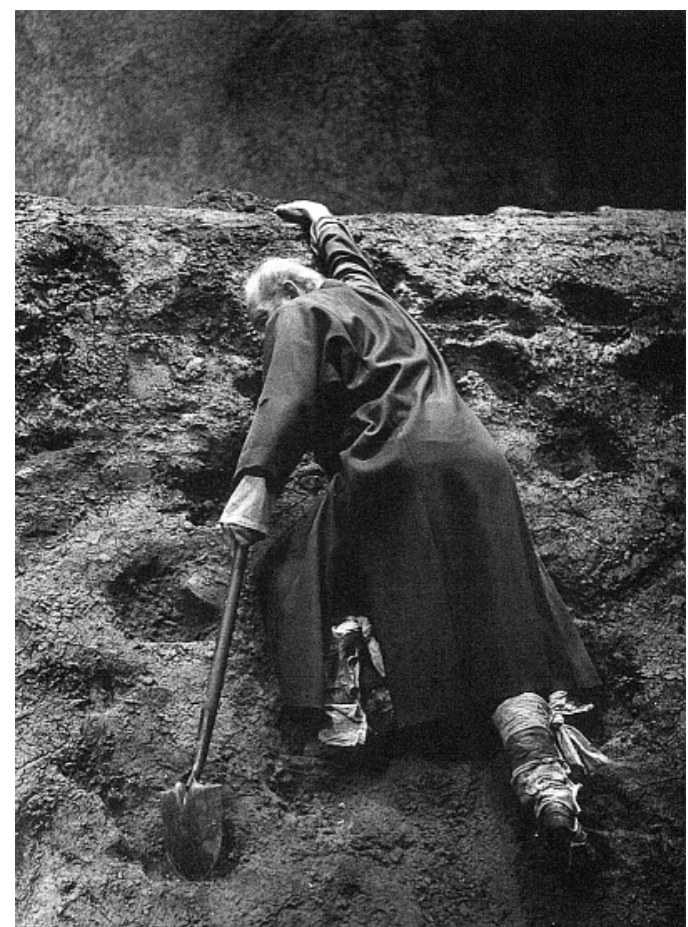

Limpando o espelho (Cleaning the Mirror) performance de Marina Abramovici, 30 de Novembro de 1995 fot. Sean Kelly Gallery, Nova lorque cortesia da artista e da Sean Kelly Gallery].

Lear,

de Edward Bond, enc. William Gaskill, Royal Court Theatre, 1971 (Harry Andrews), fot. John Haynes.

Mas o texto de Crimp é mais do que uma evocação satírica de tais experiências no domínio das artes visuais - algumas delas, com importantes ligações ao universo da performance. Nessa mesma cena, o dramaturgo consegue dar voz a reacções muito distintas a uma proposta tão radical, entre as que vêem nela "pura auto-indulgência" e as que a consideram "uma obra que marca uma época", listando uma série de adjectivos só aparentemente contraditórios, que podem servir para caracterizar muita da criação contemporânea:

- É comovente. É oportuna. É perturbadora. É engraçada. É doentia. É sexy. / É profundamente séria. É divertida. É criptica. É obscura. É altamente pessoal e ao mesmo tempo levanta questões vitais sobre o mundo em que vivemos. (Ibidem: 192)

Perto do fim da cena, esta discussão é alargada ao teatro. Respondendo à voz mais crítica, que insistia que "toda a sua obra se torna uma mera representação cínica e é duplamente repugnante", uma outra voz, mais
Naturalmente, esta e outras traduções, quando não identificadas de outro modo na bibliografia, são de minha responsabilidade. 0 mesmo se aplica aos titulos de algumas peças que nunca tiveram tradução portuguesa.

${ }^{2}$ Entre os artistas responsáveis pela polémica pública, que conseguiu levar o habitualmente restrito mundo das artes visuais a um público mais alargado, podem referirse os nomes de Helen

Chadwick, Tracey Ermin, Chris Ofily ou Damien Hirst. 


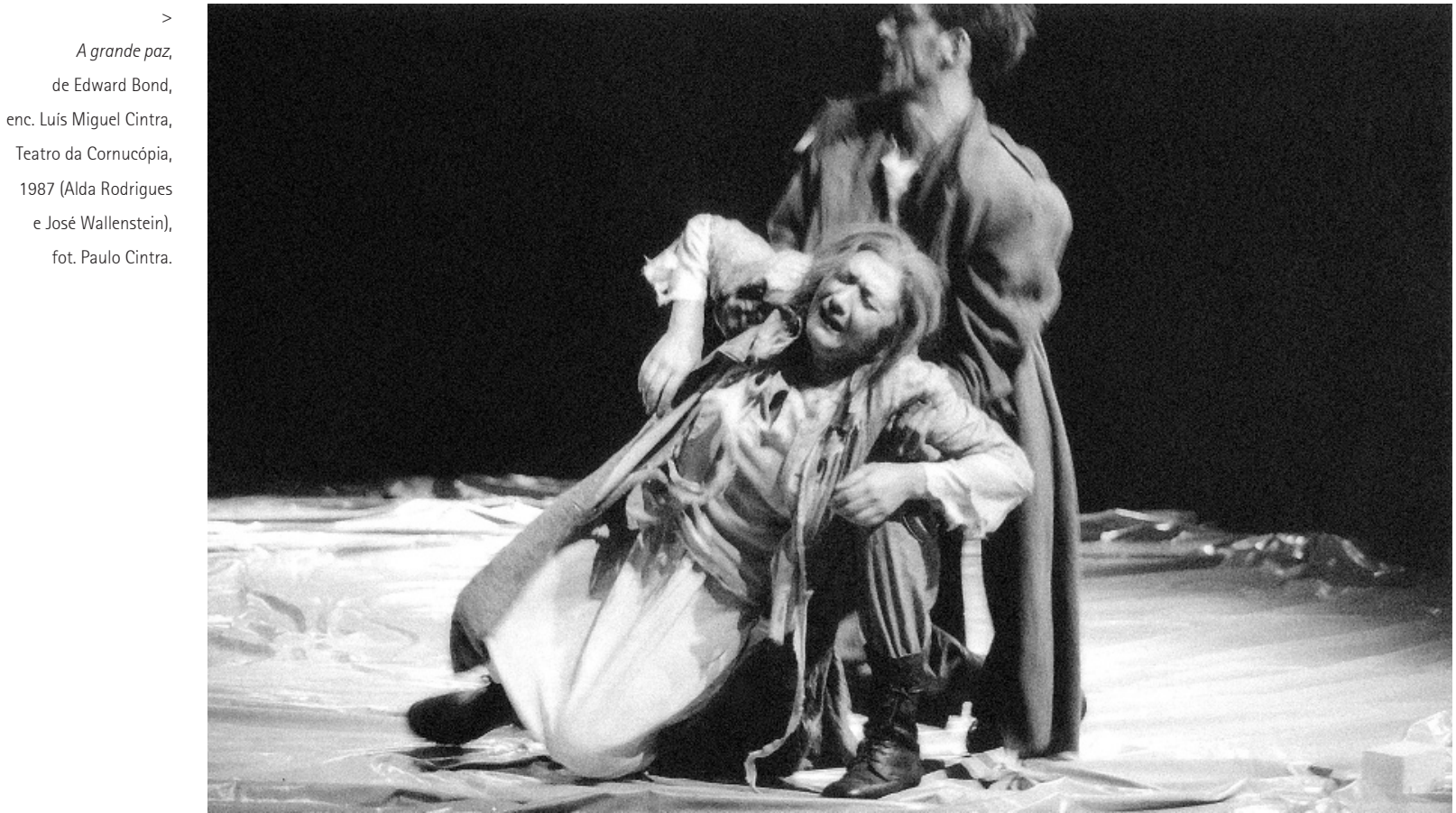

Martin Crimp, fot. Karen Kopinski. empenhada na defesa do valor da obra da artista, expande a analogia aos domínios das artes performativas, sugerindo:

\begin{abstract}
- É teatro - exacto - para um mundo no qual o próprio teatro morreu. Em lugar das convenções ultrapassadas do diálogo e das chamadas personagens arrastando-se para os embaraçosos desenlaces do "teatro", Anne oferece-nos um puro diálogo de objectos: de couro e vidro, de vaselina e aço; de sangue, saliva e chocolate. Ela oferecenos nada mais nada menos do que o espectáculo da sua própria existência, a "pornografia" radical - se é que posso usar esta muito estafada palavra - do seu próprio corpo partido e abusado - quase cristico. (Ibidem: 192-193)
\end{abstract}

Numa reacção final à acusação de que todos nós teremos "já visto isso tudo no chamado 'radicalismo' dos anos sessenta barra setenta", uma outra ou a mesma voz citada antes acrescenta:

\section{- Visto - talvez. Mas não visto de novo, não visto agora, não visto no contexto de um mundo "pós"-radical, pós-"humano" onde os gestos do radicalismo assumem um novo significado numa sociedade na qual o gesto radical é simplesmente mais uma forma de divertimento, isto é, mais um produto - neste caso um objecto artistico - para ser consumido. (Ibidem: 194)}

Esta troca de argumentos é não só um brilhante exemplo metadramático de consciência artística - crucial no contexto de uma peça cujas audácias mais radicais consistem na eliminação de personagens individuais e na composição de uma série de argumentos caleidoscópicos em torno de uma protagonista ausente - Anne -

sucessivamente identificada com uma artista suicida, uma terrorista, uma estrela de cinema pornográfico, uma militante new age, um carro, etc. -, mas também uma das mais lúcidas caracterizações de algumas das tendências do teatro contemporâneo, particularmente aquele no contexto no qual Crimp trabalhava, isto é, o teatro britânico de meados dos anos noventa. (A)tentados condensa no seu título ambíguo tanto o retrato cru do mundo violento
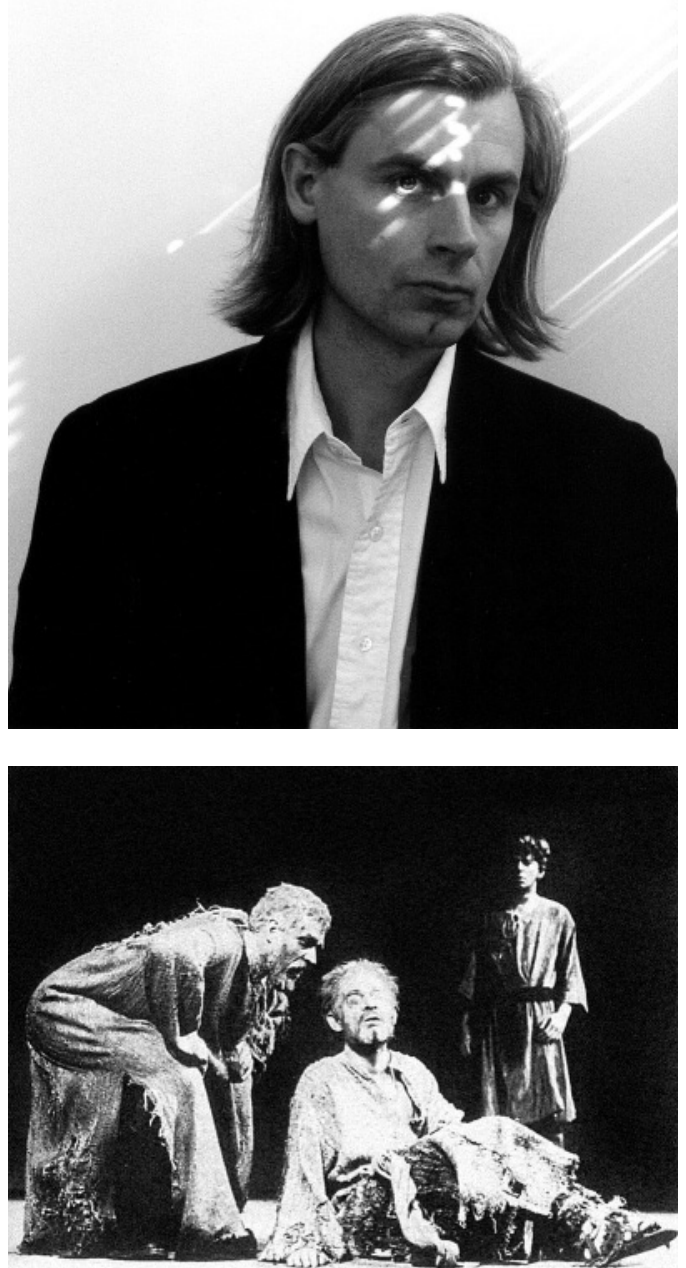


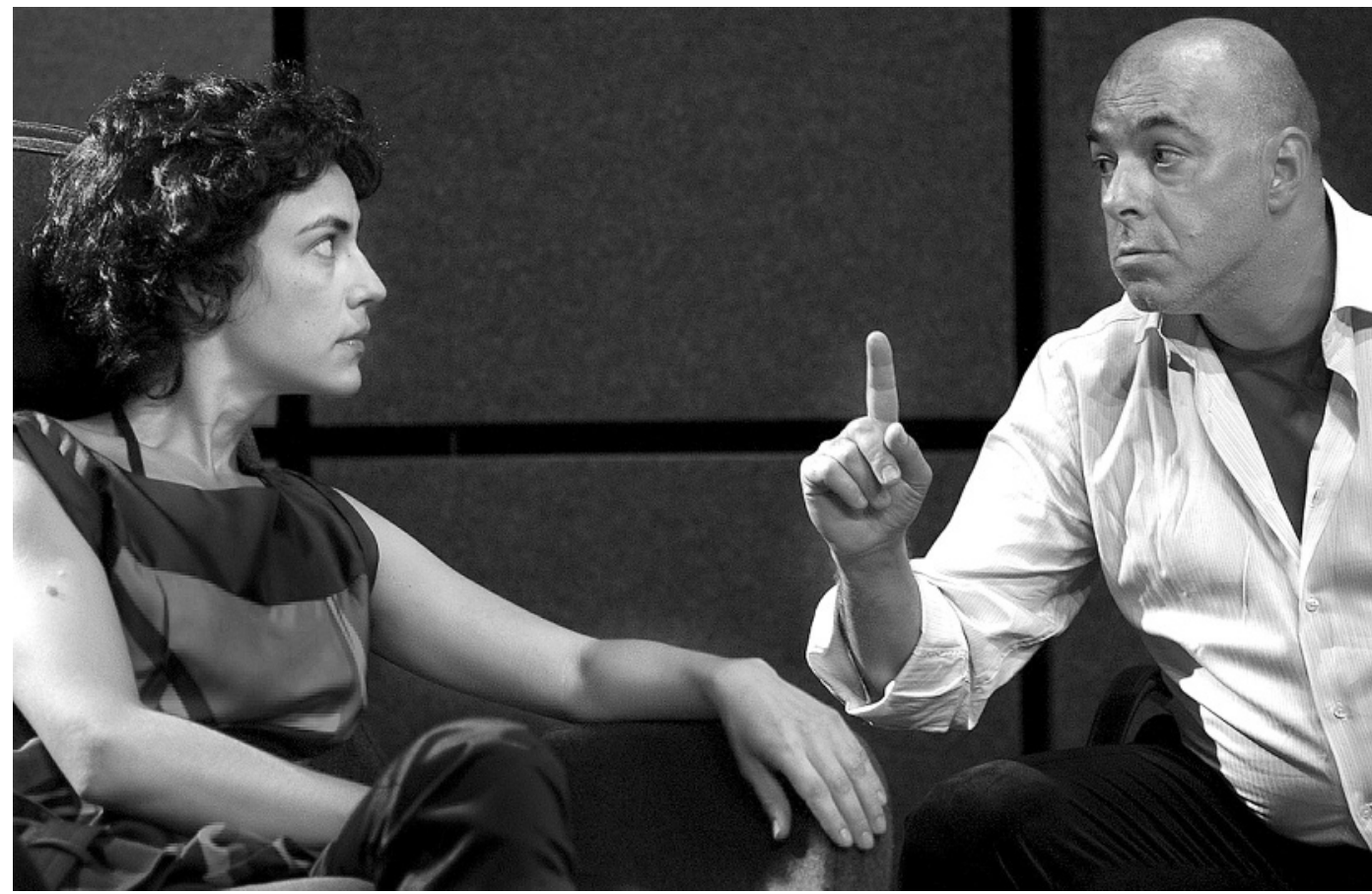

em que todos vivemos, como o reconhecimento de que, talvez, o teatro no final do último milénio não pudesse ser mais do que isso, uma série de "tentativas", e já não uma ficção organizada, oferecida aos espectadores com base na ideia de que o que eles vão ver é real - muito embora num outro momento da mesma peça esta dimensão do teatro seja igualmente discutida:

- É claro que não existe nenhuma história para contar... (...) ... nem personagens. (...) Certamente que não num sentido convencional.

(...) Mas isso não quer dizer que não seja necessária alguma habilidade.

(...) Uma vez que nós continuamos a precisar de sentir que aquilo que vemos é real. (...) Não é só representação. (...) É, de facto, mais exactidão do que representação - pela simples razão de que está realmente a acontecer" (Ibidem: 210)

Independentemente da nossa opinião sobre a peça de Martin Crimp - e a minha é que ela permanecerá como uma das experiências mais radicalmente inovadoras da dramaturgia ocidental do final do século XX -, penso que todos poderemos estar de acordo relativamente ao modo como no texto se diagnosticam alguns dos já referidos desafios que se colocam ao teatro contemporâneo, mais precisamente, a situação impossivel a que parece estar condenado: a necessidade de renovar a sua convicção numa arte de alcance humanista - ou, dito de outra maneira, de reafirmar a dimensão humana da humanidade que é a sua matéria - e, ao mesmo tempo, a obrigação de se ocupar e até mesmo de revelar a inumanidade que acompanha a nossa experiência colectiva, nas suas diversas configurações históricas. Encarada nesta perspectiva, uma peça como (A)tentados apresenta-se como sintoma de uma crise mais vasta que afecta todas as questões ligadas à violência destrutiva e até mesmo à "simples" brutalidade: uma crise de representação. A reacção sofisticada encontrada por Crimp face à sua consciência da impossibilidade de representar o mundo em toda a sua crueldade foi a de explorar a capacidade da voz para criar espectros de realidade, uma estratégia que também the permitiu preservar algum espírito lúdico, humor e, frequentemente, ironia.

Neste sentido, seria possível considerar que o teatro de Crimp é pós-dramático - não tanto de acordo com a visão de Hans-Thies Lehman (2002), que interroga sobretudo a fixidez do texto escrito, mas talvez mais na esteira da sugestão de Jean-Pierre Sarrazac (2002) relativa à permanente necessidade de renovação - por vezes, radical - das formas dramáticas. Alguns dos contemporâneos do dramaturgo britânico, com uma distinta convicção nos espaços de realidade que o teatro é ainda capaz de criar, têm explorado áreas interditas da representação, desse modo propondo novas imagens verbais ou visuais, extremamente poderosas, muitas vezes também perturbadoras, empenhadas em renovar a capacidade do teatro em transmitir visões provocatoriamente mais distópicas do mundo. No contexto da tradição britânica, entre os dramaturgos que anteciparam as experiências audaciosas da geração mais nova que se revelou em meados dos anos 90, encontramos, entre outros, os nomes de criadores como Edward Bond, Howard Brenton e Howard Barker.

Os "efeitos agressivos" de Bond tornaram-se tão conhecidos como as suas posições face a uma era dominada pela banalização, servidas pela funda convicção de que só poderemos permanecer humanos se formos radicais. Neste sentido, ele terá sido um dos primeiros dramaturgos britânicos a reconhecer na violência cénica uma dimensão indispensável do teatro contemporâneo, justamente porque:

A violência molda e domina a nossa sociedade e se não deixarmos de ser violentos não teremos futuro. As pessoas que não querem que os escritores escrevam sobre a violência querem impedi-los de escrever sobre nós e o nosso tempo. Seria imoral não escrever sobre a violência. (Bond 2000a: 34)

Edward Bond regressava, assim, às lições de alguns dos gregos e dos romanos antigos, bem como dos isabelinos 
Ruinas

(Zerbombt / Blasted)

de Sarah Kane,

enc. Armin Petras,

Schauspielfrankfurt, 2003,

fot. João Tuna. e jacobitas, para desenvolver um projecto complexo que se apresentava como simultaneamente ético e estético, baseado na renovação das modalidades de representação de actos bárbaros. A inclusão em algumas das suas peças de cenas violentas e horríficas, como o apedrejamento do bebé em Salvo (Saved, 1964) ou o canibalismo em Amanhecer (Early Morning, 1967), apresentava-se como uma estratégia de desafio potencialmente conducente a novos tipos de consciência. Há algo na démarche artística do dramaturgo que antecipa a referida crise de representação. Independentemente da nossa opinião sobre o sucesso das suas propostas e posições, aquilo que importa sublinhar é que tudo foi feito com base numa convicção quase espiritual na necessidade de renovar os poderes do teatro:

\footnotetext{
Todos nós - mesmo os que nasceram depois - somos sobreviventes de Babi Yar, Auschwitz e Hiroshima. Não é certo que todos sejamos capazes de sobreviver a "este" século, que a qualidade do que é ser humano sobreviva à violência e à banalidade. Temos de criar um novo teatro. Será diferente dos teatros dos gregos e dos jacobitas, mas servirá o mesmo propósito: criar a imagem humana. É por isso que temos de aprender a acreditar novamente no teatro. (Bond 2000b: 170)
}

Numa entrevista concedida ao jornal londrino The Independent, na semana de estreia de Ruinas (Blasted, 1995), Sarah Kane confessava:

Quando li Salvo, fiquei profundamente chocada com o bebé a ser apedrejado. Mas depois pensei... se alguém diz que não podemos representar alguma coisa, então... está a negar a sua existência, e isso é uma coisa extraordinariamente ignorante de se fazer. (apud Saunders 2002: 1996)

Penso que aquilo que estou a tentar dizer é que, no caso destes dramaturgos, o retrato linguístico e visual da violência surge paralelamente a um sentido de propósito moral e a uma necessidade de revitalização dos poderes

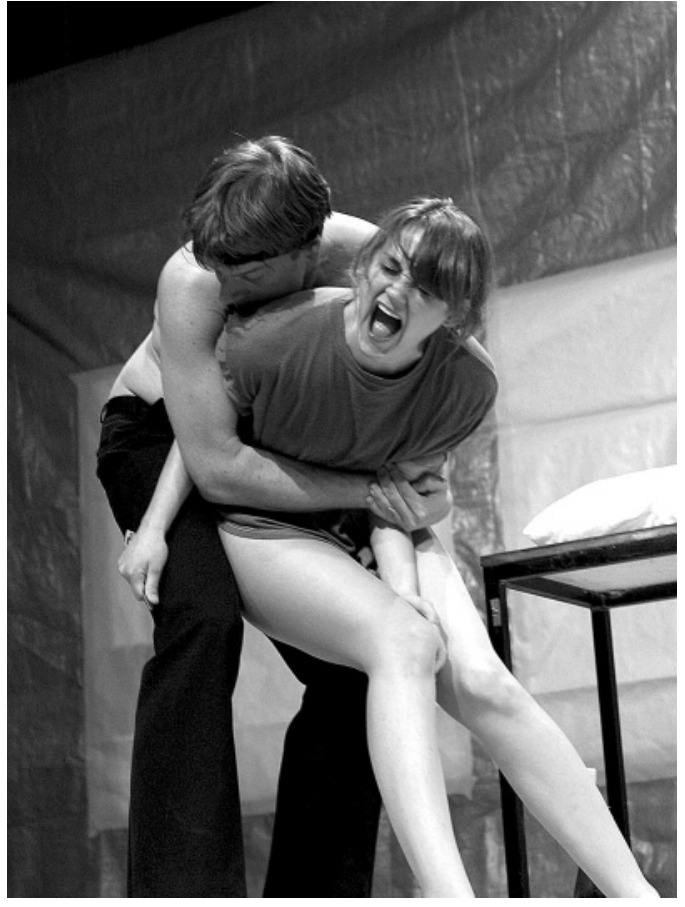

expressivos do teatro e do seu potencial comunicativo. Nada disto será novo em termos históricos, mas, para regressar a Crimp, a verdade é que se manifestou com uma renovada intensidade e um empenho partilhado na última década do século XX - confirmando a sugestão de David Edgar de que "o grande projecto do teatro britânico desde 1956, isto é, a 'anatomização da sociedade contemporânea' tem conseguido sobreviver através de uma sucessão de novas 'vagas'" (Edgar 2003). As formas apresentaram-se variadas e podiam ir desde uma estilização refinada até a um tipo mais cru de realismo, quando não mesmo de hiper-realismo. Ultrapassando os modelos aristotélicos da catarse ou os mecanismos de "distanciamento" brechtianos, muitos destes dramaturgos mostravam-se apostados numa experiência mais visceral, de ressonâncias quase artaudianas, que explica as diferentes propostas de caracterização que foram recebendo como os "Novos Jacobitas", os "Novos Brutalistas" ou os praticantes de um teatro "atirado-para-a-cara" ("In-YerFace") - a designação que conquistaria maior popularidade devido ao sucesso do livro de Aleks Sierz, publicado em 2000.

0 facto de muitas das questões abordadas por estes dramaturgos nas suas obras se prenderem com o mundo consumista e globalizado em que quase todos nós vivemos tornou algumas das suas peças particularmente atraentes tanto para os criadores teatrais como para os espectadores dos mais variados paises. A atenção concedida a alguns destes dramaturgos britânicos foi talvez maior em culturas teatrais com uma dramaturgia nacional menos expressiva, como terá sido o caso de Portugal, cujos actores e encenadores há já muitas décadas vêm contribuindo para uma renovação e actualização dos repertórios escolhendo justamente estes autores.

Entre a geração mais jovem, todas as peças de Sarah Kane - Ruinas, 0 amor de Fedra, Purificados, Falta e 4.48 Psicose - foram encenadas em Portugal, nalguns casos mais de uma vez. Um outro bom exemplo é o de Mark Ravenhill, do qual os espectadores portugueses já puderam 


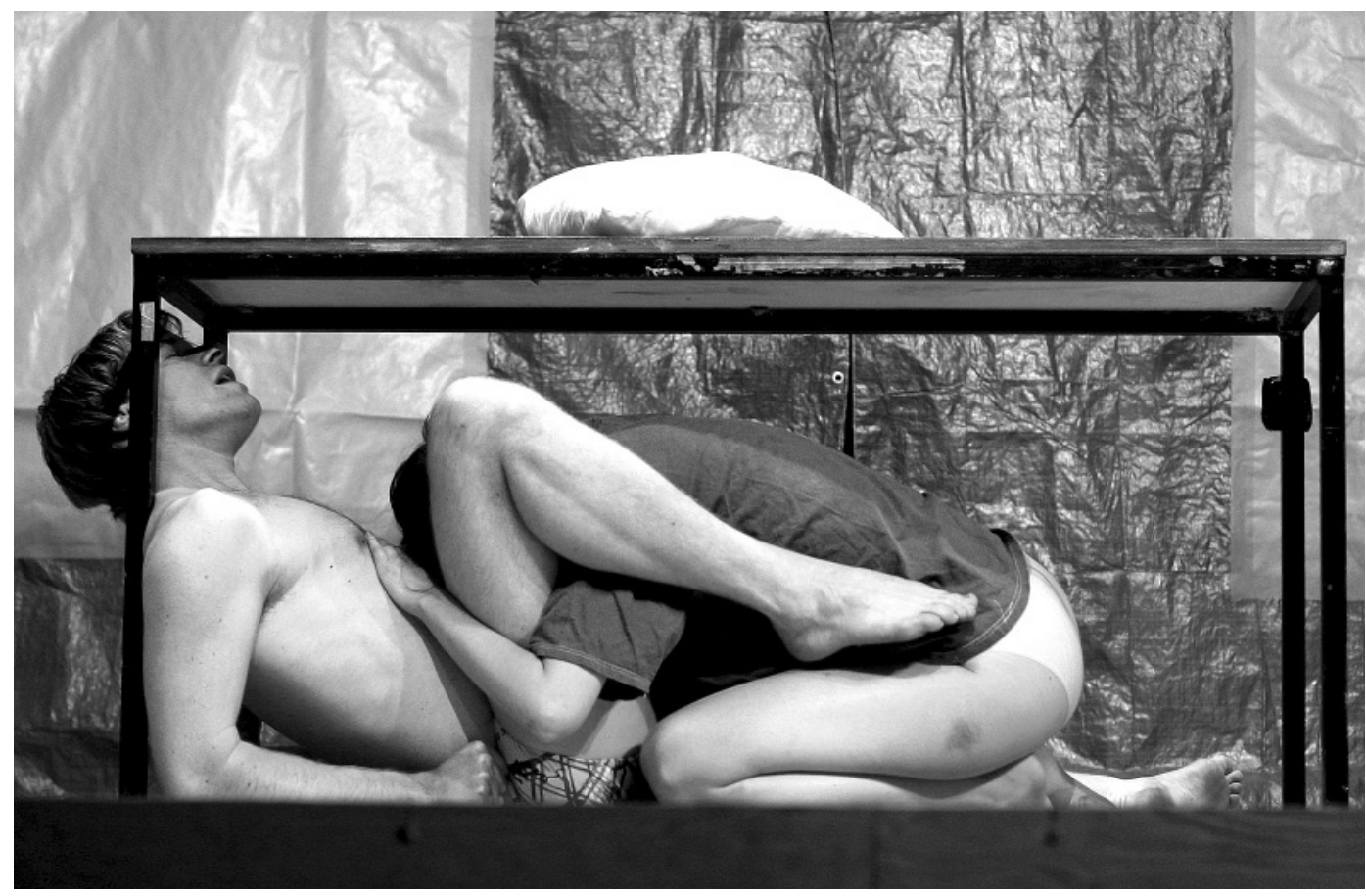

ver Comprar e foder (por duas vezes, em 1999 e 2006 com título em inglês e em 2007, sob o título Foder e ir às compras), Algumas polaróides explícitas, Fausto morreu, 0 produto e 0 corte. Outros casos mais isolados incluem as criações de Pêssegos, de Nick Grosso, Quase (Closer), de Patrick Marber, Azul/Laranja, Marcas de sangue (Bruises), de Judy Upton, e até algumas das peças de Martin McDonagh, com destaque para o mais recente The Pillowman: 0 homem almofada. A obra de dramaturgos britânicos de gerações anteriores com algumas afinidades éticas ou estéticas com esta geração foi também sendo representada em Portugal, com alguma regularidade, como é o caso de Edward Bond, Howard Barker, Caryl Churchill ou Harold Pinter. ${ }^{3}$

Muitos outros exemplos poderiam ser evocados, mas o meu principal interesse aqui é o de registar a presença significativa de muitas destas peças nos palcos portugueses. Outros dramaturgos estrangeiros que partilham algumas das características da geração britânica referida acima muitos dos quais sofreram a influência formativa do Royal Court Theatre, em Londres - têm também atraído a atenção dos nossos encenadores e actores, como é o caso de Parasitas e Cara de fogo, de Marius von Mayenburg, de Terrorismo e Brincando com a vitima (que teve por título em português No papel da vítima, em 2004), dos irmãos Presniakov, ou de Plasticina, de Vassili Sigarev.

Naturalmente, entre estas peças encontramos algumas que exibem um uso mais cuidadosamente estruturado da violência e outras que tendem a fetichizá-la, promovendo uma quase glamurização voyeuristica dessa mesma violência, com resultados muito pouco interessantes. Tal como Aleks Sierz oportunamente observou, embora seja possivel reconhecer que a utilização do tabu e da provocação torna algumas destas peças intrinsecamente políticas, devemos também reconhecer que esta intensidade corre o risco de produzir um teatro simultaneamente trivial e voyeurístico (cf. Sierz 2002: 12).

Do ponto de vista da crítica de teatro, alguns dos aspectos mais interessantes envolvidos na discussão das produções portuguesas de algumas daquelas fições estrangeiras prendem-se tanto com a avaliação do seu impacto numa outra sociedade e cultura, como com a identificação das estratégias cénicas utilizadas pelos nossos criadores para lidar com as expressões verbais e visuais da violência, tão dominantes em algumas delas. Qualquer reflexão sobre a gratuitidade ou, pelo contrário, a expressão consequente da violência nesses textos poderá conhecer interessantes desenvolvimentos se articulada com um levantamento do modo como encenadores e actores têm conseguido lidar com situações destinadas, a maior parte das vezes, a despertar as consciências, através da produção de efeitos específicos, também sensoriais, sobre o público.

0 problema com a representação da violência no teatro é que ela tem de escapar tanto à superficialidade como à vulgaridade, buscando um tipo muito particular de intensidade que deverá variar de acordo com a peça e as estratégias convocadas pelo seu autor, mas que terá sempre de ser capaz de se erguer acima da banalização a que sistematicamente a condenam os mecanismos mediáticos do nosso mundo contemporâneo. A violência apresenta-se, assim, como um desafio extraordinário para a qualidade liminal do teatro: justamente porque a realidade de qualquer situação no teatro é ao mesmo tempo um facto e uma ficção, tanto o dramaturgo como aqueles que dão voz e corpo à sua ficção têm de saber explorar o extraordinário potencial imaginativo e criativo desse espaço de liminalidade absoluta que é o palco. A representação da violência apresenta-se como particularmente apta para trazer de volta, ou para sublinhar, a dimensão de acontecimento de que o teatro parece tantas vezes - orgulhosamente - afastado. Verbalmente enunciada ou fisicamente representada, a violência no teatro parece só justificada - isto é, resgatada da banalidade em que muita da indústria do divertimento a converteu - quando abre algum tipo de espaço para novos entendimentos.

Na minha opinião, isso implica um equilíbrio delicado e um controlo informado das muitas linguagens envolvidas
${ }^{3}$ Para um levantamento mais exaustivo e rigoroso consulte-se a CETbase: www.fl.ul.pt/CETbase/ default.htm. 


\section{The Pillowman: O homem almofada, de Martin McDonagh, enc. Tiago Guedes, Teatro Maria Matos,} 2007

(Gonçalo Waddington), fot. João Tuna.

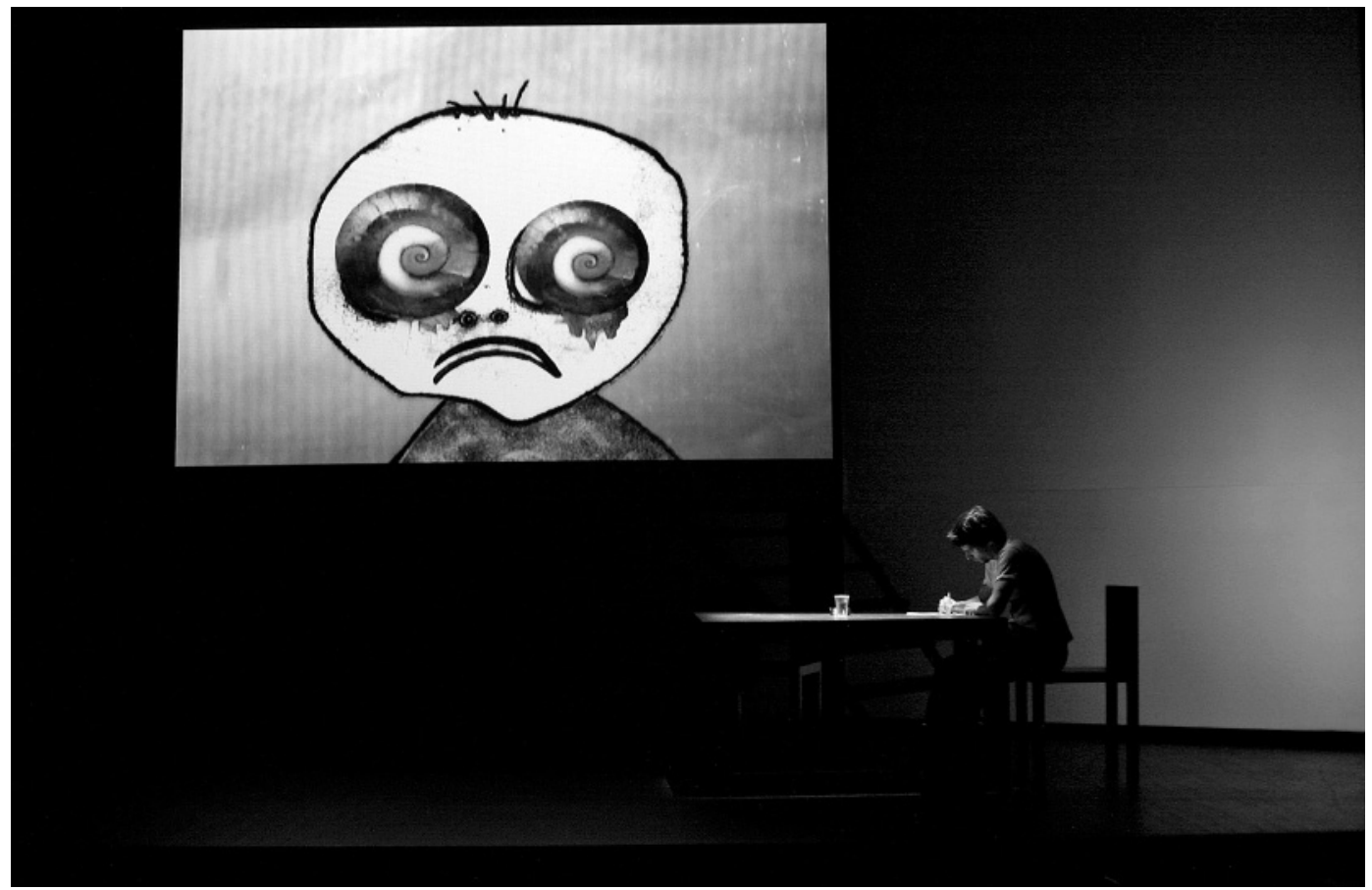

na criação e comunicação teatral, de modo a que a percepção do espectador possa ser correctamente orientada no sentido intelectual e/ou sensorial do que é dito ou fisicamente expresso em cena. No caso do teatro ainda baseado na encenação de alguma ficção dramática que Ihe preexiste, o processo através do qual as palavras são reforçadas, alargadas ou eventualmente anuladas é sempre muito delicado, dado o potencial envolvido em todas as outras expressões não verbais.

Baseado na experiência das encenações portuguesas de algumas das peças identificadas atrás, arriscaria a dizer que existe muitas vezes uma reticência na nossa prática teatral em lidar de um modo mais ousado e radical com alguns dos desafios violentos representados por esses textos. Uma reticência que, nos melhores dos casos, pode também conduzir a experiências teatrais que se apresentam como mais "poéticas" e simultaneamente mais intelectual e emocionalmente desafiadoras do que a simples leitura das peças poderia sugerir. Mas, noutros casos, a opção pelo que pode parecer uma abordagem mais "humanista" a ficções aparentemente pessimistas ou niilistas pode também resultar numa trivialização dos propósitos originais e das possibilidades abertas por essas ficções dramáticas. 0 perigo oposto é também verdadeiro, e o reforço mimético de muitos dos horrores ditos ou representados numa dada peça pode limitar-se a emprestar uma espécie de brilho pós-moderno à violência, desse modo contribuindo para a indiferença ou apatia do espectador.

0 momento em que, em Rei Lear, são arrancados os olhos de Gloucester pode ser executado de maneiras muito diversas, mas deverá sempre ser parte integral da crueldade retratada na peça que Shakespeare escreveu. 0 seu poder de perturbação poderá ser mais importante agora do que quando Shakespeare compôs a peça, porque está intimamente associado à expressão da desordem e da tirania, bem como à capacidade dos homens para a realização de actos brutais e cruéis. Seja através do medo ou do choque, a experiência da violência cénica pode ainda desempenhar um papel importante na formação de uma consciência colectiva de que o nosso mundo é, muitas vezes, abalado por acontecimentos terriveis. Para aqueles que ainda vêem no teatro uma espécie de destilação das experiências humanas concretas, então o teatro terá necessariamente de se ocupar também das suas manifestações mais sombrias. Não é tanto uma questão de acrescentar mais violência, brutalidade ou crueza ao nosso mundo, mas, como sempre em arte, de estarmos vigilantes relativamente aos meios utilizados para uma compreensão mais abrangente e, por isso mesmo, mais complexa do nosso mundo.

\section{Referências bibliográficas}

BOND, Edward (1977), "Author's Note: On Violence", in Plays One, London, Eyre Methuen, pp. 9-17

- - (2000a), Selections from the Notebooks of Edward Bond (Diaries, Letters and Essays), Vol. 1 (1959-1980), London, Methuen.

- - (2000b), The Hidden Plot: Notes on Theatre and the State, London, Methuen

CRIMP, Martin (2000), Peça com repetições / (A)tentados, trad. Paulo Eduardo Carvalho, Porto, Campo das Letras.

EDGAR, David (2003), "Secret Lives", The Guardian, 19 de Abril.

KANE, Sarah (1995), "A Very Angry Young Woman", entrevistada por Clare Bayley, The Independent, 23 de Janeiro.

LEHMAN, Hans-Thies (2002), Le Théâtre postdramatique, trad. PhilippeHenri Ledru, Paris, L'Arche.

SAUNDERS, Graham (2002), "Love me or kill me": Sarah Kane and the Theatre of Extremes, Manchester, M.U.P.

SARRAZAC, Jean-Pierre (2002), O futuro do drama, trad. Alexandra Moreira da Silva, Porto, Campo das Letras.

SIERZ, Aleks (2000), In-Yer-Face Theatre: British Drama Today, London, Faber and Faber.

- - (2002), "In-Yer-Face Theatre: New British Drama Today", Anglo Files: Journal of English Teaching, n. 126, pp. 8-14. 